\title{
Silver Anniversary: 25 Editions of the IMIA Yearbook
}

\author{
Christoph U. Lehmann, Marie-Christine Jaulent, Brigitte Séroussi
}

\begin{abstract}
Summary
Objectives: To provide an editorial introduction into the special $25^{\text {th }}$ anniversary edition of the IMIA Yearbook of Medical Informatics with discussion of the significance of the Yearbook, past and current editorial teams, and a look into the future. Methods: A brief overview of the 2016 anniversary edition of the Yearbook allows for a discussion of the significance and value of the Yearbook to the Biomedical Informatics community as well as a review of changes in Yearbook team and format over time. Results: The IMIA Yearbook celebrates its 25th edition bearing witness to the quality of the IMIA brand, the Yearbook content, as well as to the dedication of and the inordinate amount of labor from the authors and editors of the Yearbook. Editorial teams are to be applauded for their hard work and for their foresight in steering the Yearbook from a paperback to an open access online publication. The special edition provides reviews of past editorials with the knowledge of today.

Conclusions: The IMIA Yearbook celebrates a remarkable milestone providing a testament to the maturity of the Biomedical Informatics field. Informaticians across the world are encouraged to thank past editorial teams and celebrate with IMIA.
\end{abstract}

\section{Keywords}

International Medical Informatics Association, Yearbook, silver anniversary, biomedical informatics

Yearb Med Inform 2016;Suppl1:S3-5

http://dx.doi.org/10.15265/IYS-2016-s041

Published online May 20, 2016

\section{Silver Anniversary}

Please celebrate with us the $25^{\text {th }}$ Anniversary of the IMIA Yearbook. In our relatively young field, 25 years of publishing an annual book in Biomedical and Health Informatics is an extraordinary achievement and a mark of perseverance and quality. Twenty-five years of the IMIA Yearbook show the maturity of the field, corroborate the quality of the IMIA brand, confirm the quality of the content, and demonstrate the dedication of and the inordinate amount of labor from the authors and editors of the Yearbook. So, please extend your congratulations to IMIA and be one of the first to offer your best wishes on the IMIA Facebook page.

\section{Significance}

The significance of the Yearbook to the field of Biomedical Informatics is hard to overestimate. Every year, experts in the various domains review the literature of the last year and highlight in one place the most important works, allowing others to quickly identify the seminal publications in the domain for the prior year. Every year's special section focuses on a particular relevant topic that is timely and important. Historical reviews and news from the different IMIA regions round out the content of the Yearbook.

\section{Special Edition}

This year, we will have a special edition of the Yearbook. Besides our regular edition, we have an Anniversary Edition, which includes leaders in our field rethinking their keynote papers from the past. We will also

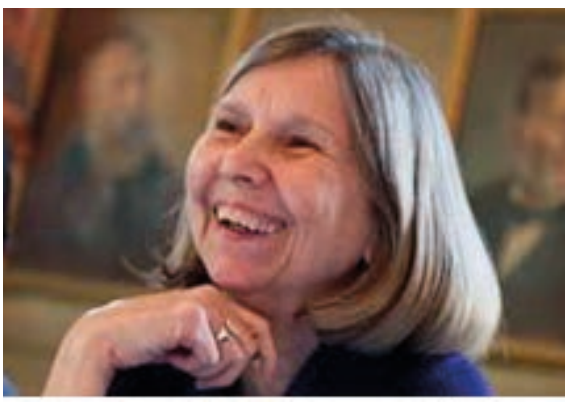

Fig. 1 Alexa Mccray

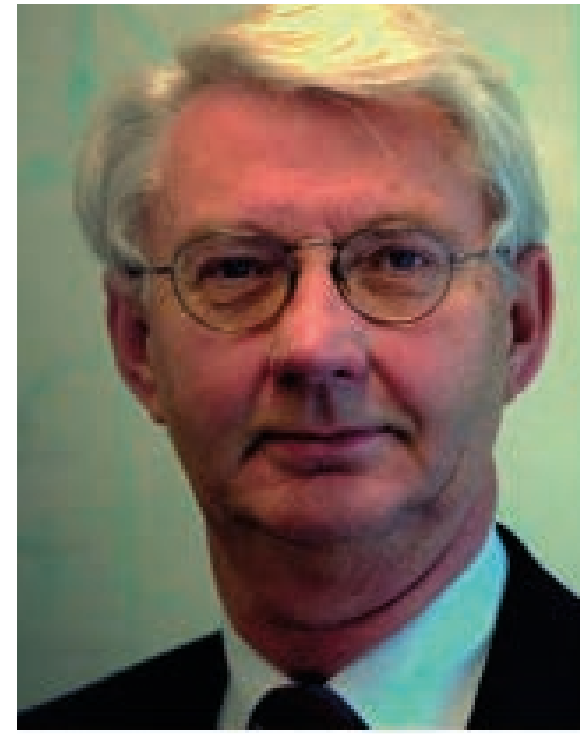

Fig. 2 Jan van Bemmel

feature review papers on the main domains of Biomedical Informatics that look back at 25 years to describe where these domains were in 1992, explore the barriers and incentives that shaped their evolution until today, and dare to predict the changes in the coming 25 Years. This should make interesting reading for the future editors of the $50^{\text {th }}$ anniversary edition of the Yearbook. 


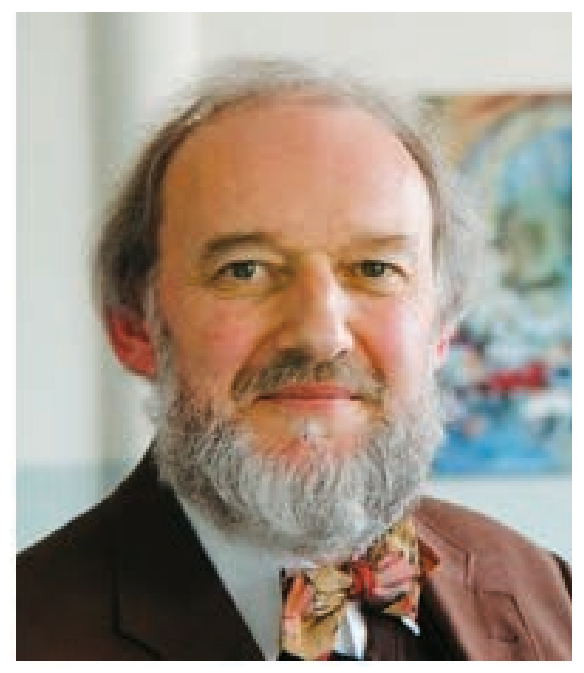

Fig. 3 Reinhold Haux

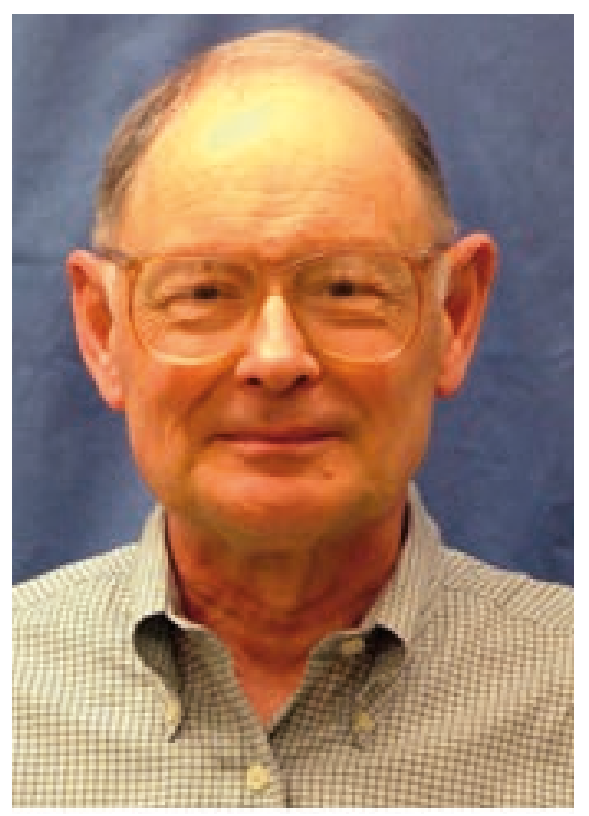

Fig. 4 Casimir Kulikowski

\section{Past Editorial Teams}

Of course, at such an important milestone, we have to mention the individuals, who established and guided the yearbook. Praise must

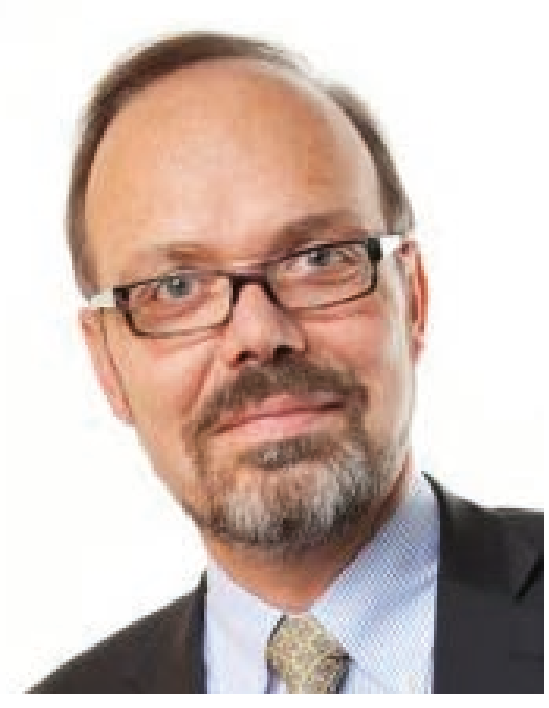

Fig. 5 Antoine Geissbuhler

go to Alexa McCray (Figure 1) and Jan van Bemmel (Figure 2) - the first editors of the Yearbook, who still show great interest in its operation and well-being. Other important individuals, who were important stewards of the Yearbook, include Reinhold Haux (Figure 3), Casimir Kulikowski (Figure 4), and Antoine Geissbuhler (Figure 5). With the current team of Marie-Christine Jaulent, Christoph Lehmann, and Brigitte Séroussi, for the first time in its history does the Yearbook have a majority female leadership.

The unsung heroes of the Yearbook are the managers of the Editorial Office. Past managers include Desiree IM de Jong (1992 - 1999, Figure 6) and Rosa JJR Scholte (1992 - 1999, Figure 7) from the Erasmus University. This editorial team wants to thank Martina Hutter (2000 - Present, Figure 8) for her tremendous contribution, for her dedication, her ability to hold us accountable and to deliver on time. Without her, the Yearbook would not be possible. Thank you, Martina!

\section{Yearbook Format}

The Yearbook's format has changed over the years. Initially printed and distributed as a paperback at IMIA conferences like MedInfo, the Yearbook went to free online access in 2014 - an achievement we are proud of since it allows all IMIA members, including those in resource poor areas of the globe, to use the valuable articles. The current editors thank the IMIA Board and the General Assembly for their wisdom, foresight, and generosity to make this possible!

Gratitude is also in order for the wonderful contributions by Professor Haux and the Peter L Reichertz Institute in Braunschweig for bringing the old Yearbook editions online in an open access format. As we are writing this editorial, copies of past Yearbooks are being scanned, and will be available online in part due to the help and generosity of our friends at Schattauer Publishing.

\section{Looking into the Future}

Looking at the 12-year reign of Prof. Kulikowski as editor of the Yearbook, at least one member of the current editorial team is embarrassed of leaving after only four years to take over the position of IMIA president in 2017. Being a Yearbook editor is a great challenge but also an enormous honor and we are proud to serve the IMIA and the Biomedical Informatics community. Please be merry with us this fall at the IMIA General Assembly as we celebrate the 25 years of the IMIA Yearbook!

Chris, Marie-Christine, Brigitte 

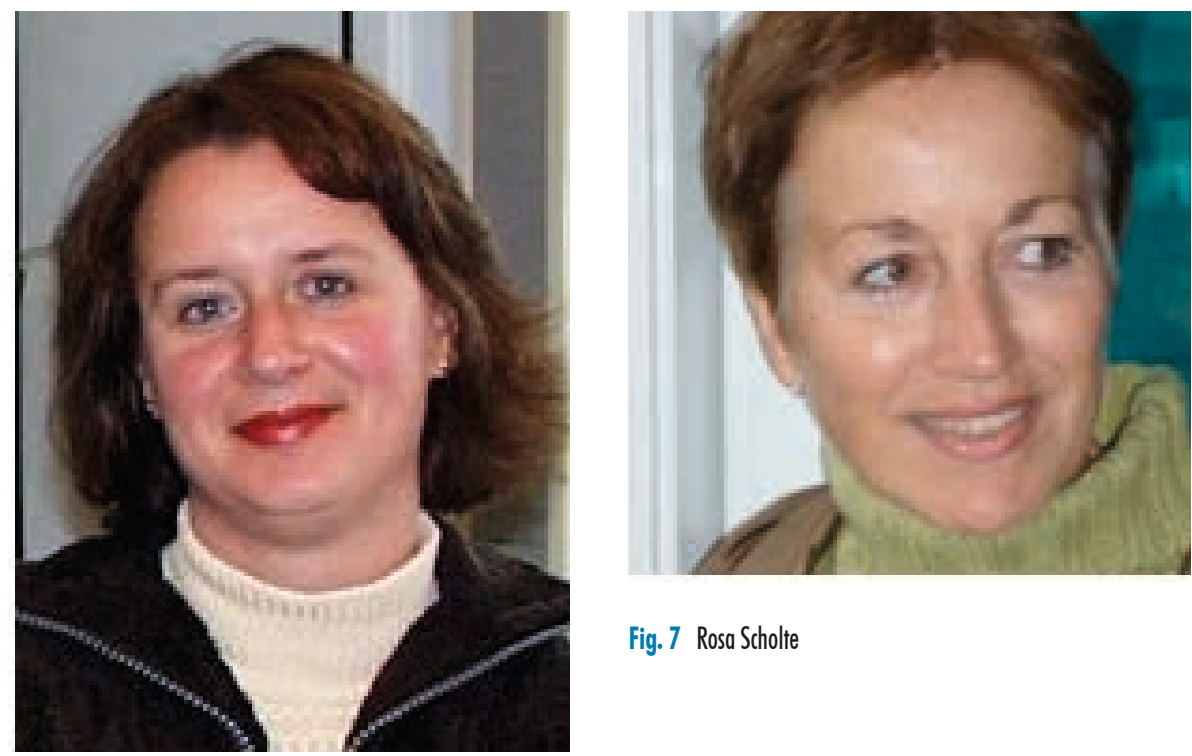

Fig. 7 Rosa Scholte

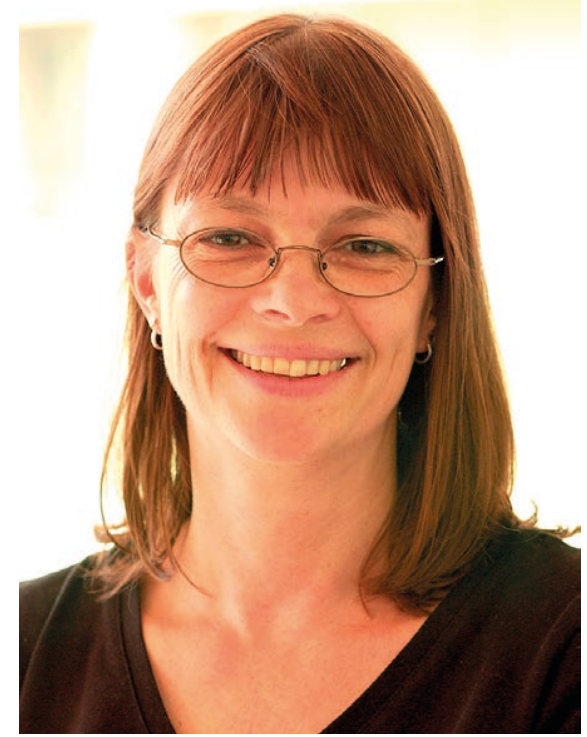

Fig. 8 Martina Hutter

Fig. 6 Désirée de Jong

Table 1 MIA Yearbook editions, their special topic, and their editors

\begin{tabular}{|c|c|c|}
\hline Year & Special Topic & Editors \\
\hline 1992 & Advances in an Interdisciplinary Science & Jan van Bemmel, Alexa McCray \\
\hline 1993 & Sharing Knowledge and Information & Jan van Bemmel, Alexa McCray \\
\hline 1994 & Advanced Communications in Health Care & Jan van Bemmel, Alexa McCray \\
\hline 1995 & The Computer-based Patient Record & Jan van Bemmel, Alexa McCray \\
\hline 1996 & Integration of Information for Patient Care & Jan van Bemmel, Alexa McCray \\
\hline 1997 & Computing and Collaborative Care & Jan van Bemmel, Alexa McCray \\
\hline 1998 & Health Informatics and the Internet & Jan van Bemmel, Alexa McCray \\
\hline 1999 & The Promise of Medical Informatics & Jan van Bemmel, Alexa McCray \\
\hline 2000 & Patient-centered Systems & Jan van Bemmel, Alexa McCray \\
\hline 2001 & Digital Libraries and Medicine & Reinhold Haux, Casimir Kulikowski \\
\hline 2002 & Medical Imaging Informatics & Reinhold Haux, Casimir Kulikowski \\
\hline 2003 & Quality of Health Care: The Role of Informatics & Reinhold Haux, Casimir Kulikowski \\
\hline 2004 & Towards Clinical Bioinformatics & Reinhold Haux, Casimir Kulikowski \\
\hline 2005 & Ubiquitous Health Care Systems & Reinhold Haux, Casimir Kulikowski \\
\hline 2006 & Assessing Information Technologies for Health & Reinhold Haux, Casimir Kulikowski \\
\hline 2007 & Biomedical Informatics for Sustainable Health Systems & Antoine Geissbuhler, Reinhold Haux, Casimir Kulikowski \\
\hline 2008 & Access to Health Information & Antoine Geissbuhler, Casimir Kulikowski \\
\hline 2009 & Closing the Loops in Biomedical Informatics & Antoine Geissbuhler, Casimir Kulikowski \\
\hline 2010 & Biomedical Informatics: Building Capacity Worldwide & Antoine Geissbuhler, Casimir Kulikowski \\
\hline 2011 & Towards Health Informatics 3.0 & Antoine Geissbuhler, Casimir Kulikowski \\
\hline 2012 & Personal Health Informatics & Antoine Geissbuhler, Casimir Kulikowski \\
\hline 2013 & Evidence-based Health Informatics & Marie-Christine Jaulent, Christoph U. Lehmann, Brigitte Séroussi \\
\hline 2014 & Big Data - Smart Health Strategies & Marie-Christine Jaulent, Christoph U. Lehmann, Brigitte Séroussi \\
\hline 2015 & Patient-Centered Care Coordination & Marie-Christine Jaulent, Christoph U. Lehmann, Brigitte Séroussi \\
\hline 2016 & Unintended consequences: new problems \& new solutions & Marie-Christine Jaulent, Christoph U. Lehmann, Brigitte Séroussi \\
\hline
\end{tabular}

